\title{
Partial atrioventricular canal defect: An educational ultrasound
}

\section{image}

\author{
Aamir Jalal Al Mosawi \\ ${ }^{1}$ Advisor in Pediatrics and Pediatric Psychiatry, Children Teaching Hospital of Baghdad Medical City. \\ ${ }^{2} \mathrm{Head}$, Iraq Headquarter of Copernicus Scientists International Panel, Baghdad, Iraq.
}

* Corresponding Author: Aamir Jalal Al Mosawi, 1Advisor in Pediatrics and Pediatric Psychiatry, Children Teaching Hospital of Baghdad Medical City, Head, Iraq Headquarter of Copernicus Scientists International Panel, Baghdad, Iraq.

Received date: February 08, 2021; Accepted date: February 19, 2021; Published date: February 25, 2021

Citation: Aamir Jalal Al Mosawi. (2021) Partial atrioventricular canal defect: An educational ultrasound image. Journal of Clinical and Laboratory Research. 2(1) DOI: 10.31579/ 2768-0487/007

Copyright: @2021 Aamir Jalal Al Mosawi. This is an open-access article distributed under the terms of the Creative Commons Attribution License, which permits unrestricted use, distribution, and reproduction in any medium, provided the original author and source are credited.

\begin{abstract}
Atrioventricular canal defect results from an abnormal or inadequate fusion of the superior and inferior endocardial cushions. Both the complete and partial types of the defect are associated with the ostium primum defect in the lowermost portion of the atrial septum, left ventricular outflow narrowing and the atrioventricular valve abnormalities. The clinical diagnosis of partial atrioventricular canal defect can be confirmed by cardiac ultrasound. The aim of this paper is to preset an educational ultrasound image of partial atrioventricular canal defect.
\end{abstract}

Key words: Partial atrioventricular canal defect; educational ultrasound image

Atrioventricular septal defect which is also atrioventricular canal defect, common atrioventricular canal, and endocardial cushion defect. It results from an abnormal or inadequate fusion of the superior and inferior endocardial cushions. Both the complete and partial types of the defect are associated with the ostium primum defect in the lowermost portion of the atrial septum, left ventricular outflow narrowing and the atrioventricular valve abnormalities. Cardiac ultrasound helps in establishing the diagnosis of various types of endocardial cushion defects. Figure-1 shows an ultrasound image of an infant with partial atrioventricular.

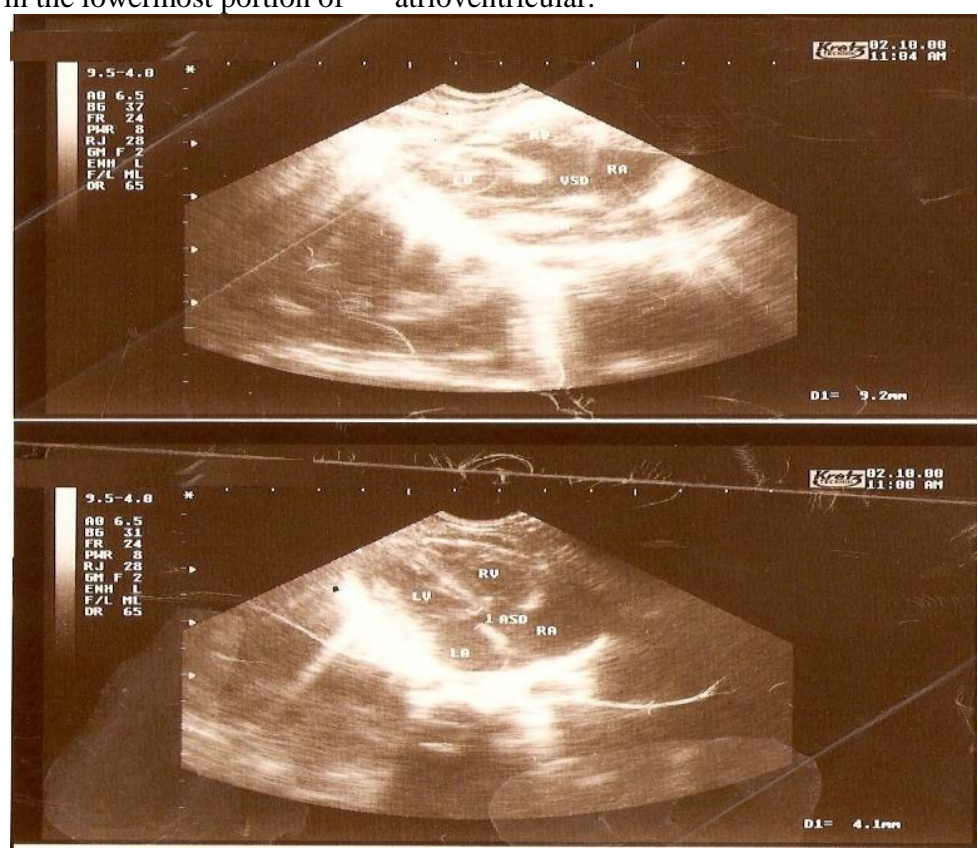

Figure 1: An ultrasound image of an infant with partial atrioventricular showing right ventricular hypertrophy, large inlet ventricular septal defect, 
The atrioventricular canal is the "classic" congenital heart defect seen in patients with Down syndrome. In Down syndrome, complete atrioventricular canal is the prevalent defect, which is commonly associated with tetralogy of Fallot.

Partial atrioventricular canal and left-sided anomalies are more common in patients without Down syndrome.

\section{References}

1. Sellors TH, (1961) Somerville W. The persistent ostium primum atrial septal defect. (Partial persistent common atrioventricular canal). Postgrad Med J 37(433):646-52. PMID: 13910481.

2. Yoshikawa J, Owaki T, Kato H, Tomita Y, Baba K .(1975) Echocardiographic diagnosis of endocardial cushion defects. Jpn Heart J 16(1):1-10. PMID: 1113447

3. Marino B, Vairo U, Corno A, Nava S, Guccione P, Calabrò R, Marcelletti C.( 1990) Atrioventricular canal in Down syndrome. Prevalence of associated cardiac malformations compared with patients without Down syndrome. Am J Dis Child. 144(10):1120-2. PMID: 2144945. 